INTERNATIONAL DESIGN CONFERENCE - DESIGN 2002

Dubrovnik, May $14-17,2002$

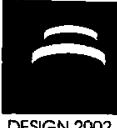

\title{
DESIGN EDUCATION IN THE INFORMATION AGE
}

\author{
and Nigel Cross
}

Keywords: Design education, Information Age, General Evolution

Theory, technological change

\section{Introduction}

Technology is a major driver of sociocultural change. Kurzweil[200I] believes that technological change has historically followed a double exponential curve (Table 1).

Table 1. Technological transformations in time

\begin{tabular}{|l|l|}
\hline Economy & Duration(years $)$ \\
\hline Hunter-gathering & 500,000 \\
\hline Agricultural & 10,000 \\
\hline Industrial & $200(1760$ s to 1950s $)$ \\
\hline Information & $75-80(1940 \mathrm{~s}-2020 \mathrm{~s})$ \\
\hline Biotechnological & $70(1970 \mathrm{~s}$ to 2040s $)$ \\
\hline Nanotechnological & $70(2020 \mathrm{~s}$ to 2090s $)$ \\
\hline
\end{tabular}

We are reaching the sharp end of this curve, with the prospect of three technological revolutions this century; the complexity and scale of these transformations is such that a 60-70 year cycle may be a minimum. We are some 50 years into the industrial/information transformation, which should mature over the next two decades. This paper speculates on the main features of design education as societies make this transformation. In doing so:

- a theoretical framework is proposed, to betler understand such transformations

- this framework is used to interpret developments in design during the industrial age

- the insights so gained and the theoretical framework are then used to predict how design may change during the rest of the information age

- these insights in tum are used to anticipate how design education might develop during the rest of the information age

\section{Underlying theoretical framework}

A theoretical framework which sheds light equally on the past. present and future trajectories of design practice is desirable; General Evolution Theory of Ervin Laszlo [1996] is used for this purpose. Laszlo posited that all dynamic systems - physical, biological. social, cognitive - have a commonality of process; his theory is, thus, inclusive of all complex adaptive systems. We can view design practice as such a system - both in its own right and as part of the much larger systems of product/service generation and, ultimately, of socioculture itself. There are several "operational" features of Laszlo's theory which can inform the interpretational task(Table 2). 
Table 2. Key features of evolving systems

* Systems which evolve must cope with progressively larger information flows(Informatization)

* A major evolutionary strategy is convergence, leading in human affairs, to

- Within the framework of convergence, divergence is an important means of creating evolutionary potential

* As systems evolve, they become more complex(Complexification)

- Coevolution, the interplay of collaboration and competition, is a key operational strategy in increasingly complex systems

- Systems experience increasing turbulence as they approach a bifurcation(decision point); the weaker bonding, and hence greater flexibility, of complex systems is an important coping mechanism at such times

- Creativity occurs particularly at the edge of chaos: as complex systems become more flexible, their creative potential increases and this creativity further accelerates their evolution

- Systems seek to optimize their function at all times

- As more complex social systems are more weakly bonded, there is an increasing need for social responsibility

3. Design practice in the Industrial Age

The Industrial Age was accompanied by significant changes in design practice, as expressed througt the emergence of design movements(Figure 1).

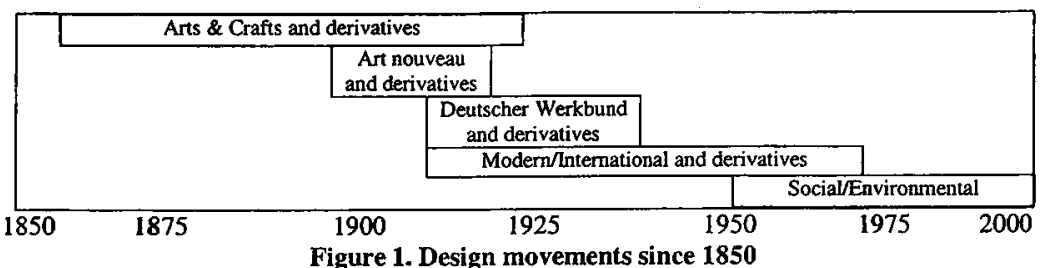

Recognising design practice as an evolving system, we can identify the key implications of this age for design practice as follows:

Informatization: Information accrual accelerated through the industrial age. Martin \& Norman [1973:26 noted: 'It has been estimated that by 1800 [the sum total of human knowledge] was doubling every 50 years; by 1950, doubling every 10 years; and that presently it is doubling every five years'. Although product development is often described as an exercise in information processing, it was not until the late 1980s that large UK firms recognized the need for extensive and timely access to information during product development[Fairhead, 1987:7].

Convergence: From often diverse craft beginnings, convergent design practice between countrie characterised the industrial age - as evidenced by the international nature of the design movements of this time. Some - like the Arts \& Crafts and Art nouveau - were ultimately evolutionary cul-de-sacs. The Deutscher Werkbund and Modernism, on the other hand, became increasingly aligned with industry. Modernism in particular has been more enduring, and more systemic in nature than earlie movements, encompassing not only the arts and design, but also aesthetics, literature, theology.

Divergenoe: Despite these convergent trends, notable divergences also occurred. For example, produc standardizaxion was adopted by the North Americans from the early 1820s(the "American System of Manufactures'), almost a century before it became a guiding principle of the Deutscher Werkbund. Divergence was even more evident in design education(see below).
Complexification: Industrialization changed the very basis of human existence and. in so doing, Concreased complexity in every aspect of socioculture. Design practice learnt to cope with increasing diversity in products, materials, manufacturing processes, markets, etc.

Coevolution: Coevolution is the practice of using both competitive and collaborative strategies to enhance survival; it is frequent in biological systems. Competition, rather than coevolution characterised business in the industrial age, with little collaboration beyond e.g. price fixing.

Turbulence: Systems experience growing turbulence as they move out of balance with their environments; this can lead to transformational events, in which the system is re-formed or collapes. Thus, the design movements of the industrial age all existed for relatively short periods of time(25-70 years), after which they collapsed or transformed into a new movement.

Creativit The slow, local incremental changes of the crat age were replaced by broadly-baed,

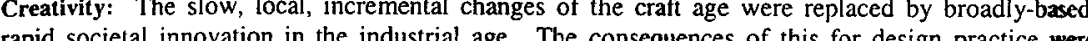
rapid soci th in dramac. 'l the past.... predecessors ... Now he last sheds of tradion are being torn from him ... Bewildered, the formmaker stands alo "... He has to be encoured to "create" the form he is concerned with, for what once took many generations of gradual development is now a templed by a single individual [Alexander, 1964:4].

Social responsibility: The design movements of the industrial era generally promoted social and moral responsibility. The Arts \& Crafts movement idealistically opposed industrialization because of the perceived tastelessness of industrial products, and of concerns about the control of technology, "joyless work", loss of skills. The Deutscher Werkbund sought to restore dignity to labour in industry and create a distinctive national style of design. The Bauhaus also had a social agenda. Nonetheless. most did not achieve their goals, and it required the widespread emergence of consumer rights organizations after World War II, and the introduction of consumer protection laws in the 1960s before designers accepted responsibility for the wider consequences of their designs. The 1970s saw the widespread emergence of concerns about design and the environment/disadvantaged. Feminist concerns with design emerged from 1980, and from the mid-1980s ecodesign developed in response to environmental concerns.

\section{Design education in the Industrial Age}

There is a history of arts and crafts education in Britain which extends over at least 250 years[e.g. Bignamini, 1990]. Despite growing references to design in this period, and multiple initiatives to promote design education, the discovery of an effective formula for design education was elusive. Much the same can be said for most other industrializing countries at the time. The strong influence of the fine and decorative arts and prevailing sociopolitical conditions worked against the manchneeded breakthrough.

It was only from late $19^{\text {th }}$ century in Germany that conditions for this breakthrough appeared. With the death of William Monis in 1896 , the initiative for han continent and the USA.

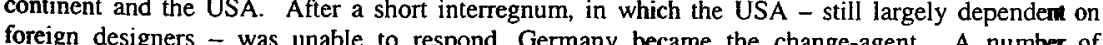
developments influence of the English Arts and the Deutsche Werkstan he Deutsche Werkstaten in 1897, the Dresdner Werkstatten in 1898); from 1900 these initiatives engaged wions ind Education for the Werkband Education Committee in 1908. When the Bauhaus formed in 1919, it initially promoted arts and confts ideals. It was not until 1922, and the arrival of Moholy-Nagy in 1923, that a clear and decisive stuff in Bauhaus ideology towards industry became evident. The effect of wider influences on the course of many staff and the Bauhaus in 1933, schy staff and students initiated similar developments elsewhere. Bauhaus ideals influenced design schools globally for another four decades or more. 
5.1 Introduction

We can anticipate three transformational technological events as the information age matures, each with huge consequences for design:

the emergence of third generation communication technologies, a process already underway which should mature around 2005

the creation of realistic virtual worlds, based on the technologies of virtual reality, augmented reality and tele-immersion, within 1-2 decades

- the realization of anytime/any place/multimedia communication by the $2020 \mathrm{~s}$

The implications of these and related developments for design are explored below.

\subsection{Elemental implications}

Informatization: it has recently been estimated that information is growing 200,000 times faster than world population [Wilson, 2001]. Such massive information flows have fundamental implications for societies, with information increasingly embedded in social and physical fabrics, and the rapid emergence of cyber economies and communities. Design practice is increasingly supported by artificial intelligence and integrated information systems, a process which will need ever more urgent development.

Convergence is now occurring at many levels of design - between design technologies(e.g. CAD, rapid prototyping, virtual reality), between process stages(research, development, production, use, disposal), between product technologies(e.g. phones/computers/internet) and functions(e.g. voice/data/ disposal), between product technologies(e.
music/video), through design globalisatio

music/video), through design globalisation. accelerating innovation and change. It is especially important in times of high uncertainty, e.g. after the introduction of a radical technology.

Complexification: Biological systems have used complexification as a means of improving environmental adaptation through time. Sociocultural systems have used similar strategies becoming comprised of more parts, more kinds of parts, and greater integration of these parts - since hunter-gathering[Tainter, 2000:6]. Product complexity may arise from the number of product functions and the extent of their interdependence, number of components, novelty of product objectives, and the task uncertainty (gap between what needs to be/is known). Process complexity arises from the nature, quantity and magnitude of the organizational tasks, and their interactivity. As time-to-market shrinks, organizational/strategic means of managing this complexity become ever more challenging.

Coevolution: Strategic alliances between firms emerged particularly from the early 1980s, as a means of gaining market advantage. They offered numerous benefits to participants, including the ponling of resources, complementation of skills, information sharing, joint problem solving, coping with the increasing complexity of products/services. Globalisation has greatly increased the use of strategic alliances in new product development.

Turbulence: Design practice is adopting more flexible stralegies to accommodate uncertainty and turbulence at many levels(e.g. regulatory, economic, political, environmental, technological).

Creativity: Wallerstein [1999: 250] has observed: 'We live in an uncertain cosmos, whose single greatest merit is the permanence of this uncertainty, because it is this uncertainty that makes possible creativity - cosmic creativity, and with that of course human creativity'. As humanity moves into increasingly turbulent times, the ability to creatively respond to emerging problems becomes ever more crucial. The capacily of humans - designers particularly - to respond accordingly will determine whether global civilisation can chart a successful course. Increasingly, human creativity will be supplemented technologically.

Optimization occurs in various ways, including through miniaturization. Trends will continue towards micromachines and nanomachines, with significant product dematerialization. Such trends will permit closer relationships between humans and their technologies(especially in medicine). improve social equity through lower product costs, permit 'nomadic' designing, facilitate embedded environments, hasten cyborgs.

Social responsibility of designers should become more comprehensive as their roles become ever more central to societal wellbeing; designers will increasingly need to create products/services consonant with all evolutionary processes of this planet.

5.3 Systemic implications

The above elemental implications are strongly synergistic. While it can be relatively easy to predict elemental futures, their interplay generates surpriseful futures (emergence). Freeman \& Louça [2001:338] talk about constellations of technical and organizational innovations, such as those noted in 5.1 which, as they move through the economic and social system 'cause profound changes in the structure as well as the occupation and skills profiles and management systems. Moresver precisely because cach chant

\section{Design education in the Information Age}

Design, it seems, is ultimately about the manipulation of complex adaptive systems. Its industrial age preoccupation with mechanistic systems will recede not only as those systems themselves develop indeterminacy but also as those systems are increasingly viewed as parts of inherently indeterminate arger systems. To the extent that complex adaptive systems are increasingly understood to follow discernible evolutionary pathways, design will become the means by which the conscious evolution of complex adaptive systems, ultimately of socioculture itself, takes place. These propositions suggest an ambitious and exciting agenda for design education in the near future, in which the following issues can be discerned:

Role of holistic sciences: Despite the inherently holistic nature of design, the conscious activity of designing has existed only in the reductionist era of science. The emergence of the holistic sciences of chaos and complexity in the mid $20^{\text {th }}$ century provides a whole new level of understanding of our world which design practice has scarcely tapped. This view implies a fundamental teappraisal of the nature of design education.

Further layering of design practice: Buchanan's[1998] four orders of design - communication construction, strategic planning, systemic integration - describe a progression of design practice of increasing complexity, increasing scale, increasing relevance to core sociocultural concerns. The holistic sciences will see new orders of design codified which further elaborate this progression. Systemicists have long recognized the deeper significance of design to socioculturele.g. Banathy, 2000]; it is timely that the societal role of design be thought afresh by designers also Wallerstein [1999:1] beleves that "the modern world-system ... has entered into a terminal crisis and is unlikely to exist in fifty years'. If so, the associated transformation will require designerly skills well years if so the asions! Such developments in design practice should find expression also in design education.

Accessible design education: As designerly approaches become more widely embedded in society, an appropriately reformulated design education should find expression in the learming of other disciplines(e.g. business, politics, science, medicine, law, agriculture) as well as in the general community.

Collaborative designing will become ever more important as growing product/process complexity engages more specializations and as end-users become increasingly involved in the design process(mass customization).

Role of virtual worlds: The technologies which create virtual worlds are developing very fast. It seems likely that within a decade or so humans will communicate as effectively in virtual worlds a hey do in the real world. This should allow most, perhaps all. of the educational tasks for which face-face contact has been considered essential to be performed virtually instead.

Towards pervasive learning: Virtual worlds will become accessible anywhere/anytime/through nany devices, making design education possible wherever the learner is in space and time. 
Life-long learning: Rapid developments in design practice call for ongoing educational responses. Educational instiutions should be more proactive in meeting this emerging need.

An "Information Age Bauhau": A rcw mold of desien educalion is need incorporates the foregoing principles. As with the craftindustrial transition, this will entail a substantive break with the past; it will be revolutionary rather than cvolutionary.

\section{Conclusions}

It remains to consider the when? where? how? of the transition in design education proposed here Based on the Bauhaus experience. which occurred some $85 \%$ of the way through the industrial age. we may expect a model of design education fit for the information age to emerge in 5-10 years. Freeman \& Louçā|2001:122] recognized 5 semi-autonomous systems in sociely - science, technology, economy. politics, ocneral culturc - following a detailed study of earlier industrial revolutions. It was the interplay of these systems which created circumstances propitious for the various breakthroughs they described, as happened for the Bauhaus and as will happen also for any new education initiasive. The rapidly escalating complexity of design practice at its leading-edge, suggests that an

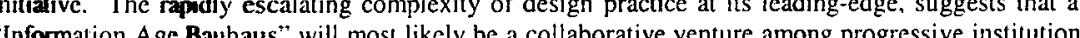
worldwide.

\section{References}

Alexander, .C., "Notes on the synthesis of form". Harvard U.P., Cambridge. Mass. 1964

Banathy, B., "Guided evolution of society: a systems view". KluweriPlenum, Nen York, 2000

Bignamini, l.e "Great Britain: first steps coward Industrial Design". In Castelnuowo, E.(Ed), "History of "Electa Milan, 1990

Buchanan, $R$., "Brawj's dilemma. design in comemporary culture", Design Issues, Vol. 14, No. 1, 1998, pp. 3

Fairhead, J., "Dexign for corporate culture". Repon prepared for the National Economic Development Council,

Freeman, C. \& Loură, F. "As time goes by", Oxford Universiry Press, Oxford, 2001

Kurcweil, $R$., "The Singulariny is near: a book précis".

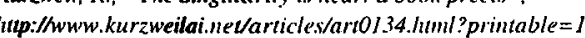

Lasslo. E. "Evolution the general theory". Hamptom, Cresskill, 1996

Manim, N. \& Norman, A. "The computerized sociery", Penguin, Londom, 1973

Taimer, J., "Problem solving: complexity, history, sustainability". Population and Enviromulent, Vol. 22, No. I, 2000, pp 3-41.

Werstein. I.. "The end of the world as we know it". University of Minnesota Press. Minncapolis. 1999.

Wilson, B. "Editorial:Challenging Times". D-Lib Magazine, Vol. 7. No.11. 2001

Hup-/sunsite anu.edu.au/mirrors/dlib/dlib/november01/1 l editorial.htum

Dr. John A. Broadbeot

Dnivesity of Technology, Sydney, Faculty of Design, Architecture \& Building.

PO Bax 123. Brotway. New South Wales Australia 2007.

Tel: (61) 29514 8986.Fax: (61) 295148787 . Email: John.Broadbent@uts edu.au
DESIGN CONFERENCE - DESIGN 2002

DESTONik, May $14-17.2002$.

\section{MODULAR PRODUCTS AND PRODUCT \\ MODULARITY - IMPLICATIONS FOR THE \\ MANAGEMENT OF INNOVATION AND FOR NEW PRODUCT DEVELOPMENT}

\section{Marco Cantamessa and Carlo Rafele}

Keywords: Modularity, product architecture, innovation

\section{Introduction}

"Modular products" have become a hol topic in a number of industries, and paricularly in automotive [AW 2001]. For instance, Volkswagen reports that, in its Resende factory in Brazil, it has adopted a modular approach to manufacturing. In this factory, industrial vehicles are made by assembling a limited number of "modules" which are locally pre-assembled by suppliers. A similar approach characterizes the way the Smart city car is made by DaimlerChrysler. In current automotive manufacturing practice it has become customary to use pre-assembled modules for elements such as cockpits (incorporating dashboard, sound system, ventilation pipes and the numerous controls and gadgets that clutter the front area of a car interior), devices associated with vehicle doors (including
latches, power windows and loudspeakers) and for bumpers (incorporating headlights and park distance control). Although the degree with which such approach is economically advantageous is nork very clear [Sako and Warburton 1999], it appears that car manufacturers are pushing ahead because they perceive that by increasing the level of outsourced labor and manuacturing equipment hey may cher

From the perspective of the engineering design scholar, this use of the word "modular" seems strikingly inaccurate. Pre-assemblies incorporating heterogeneous functionality and technology seem to negate the essence of "product modularity", which instead implies functional separation and mutual independence [Ulrich 1995]. This mismatch has not gone unnoticed, and a number of researchers have pointed out that there are different perspectives to modularity [Camuffo 2001]. While the engineering design literature focuses upon product modularity, which is associated to functional independence, modularity can also be viewed from the perspective of the manufacturing system and that of the structure given to the supply chain.

structure given to the supply chain.
The relevance of these alternative viewpoints suggests that, in product development, functionality is not the only aspect that should be taken into account when defining product architecture. As a matter not the only aspect that should be taken into account when defining product architecture. As a matter
of fact, the car industry is clearly using a criterion which is instead related to assembly. As a side note. it should also be noticed that from a criterion which is instead related to assembly. As a side note. it should also be noticed that, from the engineering design perspeclive, the architecture of today's very tight, as is the one among performance aspects and components. In other words, there are few very tight, as is the one among performance aspects and components. In other words, there are few
components to be found which are individually responsible for a given function or performance components to be found which are individually responsible for a given function or performance
indicator. From the perspective of manufacturing, instead, cars seem to lend themselves quite well to a modular architecture with a limited number of large "building blocks" which may facilitate the final modular architecture with a limited number of large "building blocks" which may facilitate the final
assembly process. The following section of this paper will discuss how the product development 